\title{
The Art of the Possible: Developing a course to INTRODUCE ENGINEERING TO NON-ENGINEERS
}

\author{
Agnes G. d'Entremont ${ }^{l}$, Patrick Kirchen ${ }^{l}$, Naoko Ellis ${ }^{2}$, Cristian Grecu ${ }^{3}$ and Sheldon Green ${ }^{l}$ \\ Departments of ${ }^{1} \mathrm{Mechanical},{ }^{2} \mathrm{Chemical}$ and Biological, and ${ }^{3}$ Electrical and Computer Engineering, University of British \\ Columbia \\ agnes.dentremont@mech.ubc.ca
}

\begin{abstract}
Understanding engineering is an important factor in fully participating in civic decision-making, however there are few opportunities for those outside engineering to learn about it. We developed and offered a course on engineering for Arts (and Commerce) students, to increase technical literacy, which counted toward the Arts degree Science requirement.

A teaching team from three disciplines presented four technical modules themed around specific technologies, and covering a wide range of engineering practice topics. Students participated in many hands-on activities and demonstrations, and instructors used flipped classroom techniques. Assessment for each module consisted of both a short technical online quiz and a blog post about a topic in the news, which allowed students to bring in their own disciplinary knowledge. The final assessment was a group video project where students aimed to advocate for a position on a technical/civic issue related to one of the modules.

We detail in this paper the results of our consultations with Arts; the course structure and goals; some of the specific content and activities designed (with an emphasis on correctly targeting pre-existing knowledge of the students); a reflection on the successes and challenges in the first offering, including student feedback; and suggestions for others who might want to develop such a course.
\end{abstract}

Keywords: Non-engineering students, arts, technological literacy, civic engagement, course development, transdisciplinary learning

\section{INTRODUCTION}

The National Academy of Engineering has argued that, in order to fully engage with civic decision-making and advocacy, citizens need an understanding of the practice of engineering[1], [2]. Our provincial Code of Ethics also mandates "extending public knowledge ... of engineering" [3]. However, the opportunities to learn about engineering from outside the field can be limited, even at institutions with engineering programs - most introductory courses are focused on providing the foundations to students in our degree programs and can be intimidating to students from other faculties, who may not have the background knowledge required for successful completion.

Recent work by the American Society for Engineering Education Technological and Engineering Literacy Division to examine the prevalence of similar courses and the challenges with offering engineering-related education to students outside of engineering and the sciences has identified several barriers to such courses, including resistance from non-technical students and other priorities for teaching resources in engineering faculties [4]. However, a number of institutions have engineeringrelated course offerings and/or specific engineeringrelated degree requirements for non-engineering students [5]. These courses and programs, most of which are recent, were found to stem from initiatives at a wide range of range of levels, from motivated individual instructors (Princeton) to university presidents (Wesleyan) [6].

Driven by interest at several levels of our engineering faculty (from individual faculty members up to and including the Dean), our team of instructors set out to develop a course (APSC 366) to teach engineering technical and practice topics to non-engineers without science backgrounds.

The first offering of the course ran January-April 2017 with five instructors from three engineering disciplines (mechanical, electrical and computer, and chemical and biological). The students registered were from a wide array of Arts disciplines, including Psychology, French, History, and English Literature, plus Commerce.

In this paper, we detail: the results of our consultations with Arts faculty and students; the course structure and goals; some of the specific content and activities designed (with an emphasis on correctly targeting pre-existing knowledge of the students and touching on how the process of distilling engineering topics for laypeople may impact how we teach those topics to engineering students); a reflection on the successes and challenges in the first offering, including student feedback; and 
suggestions for others who might want to develop such a course.

\section{COURSE ORIGIN AND DEVELOPMENT}

\subsection{Motivation}

Several faculty members and the Dean of Applied Science had a long-standing interest in improving public understanding of engineering, with a deep belief that everyone in our community needs to participate in making civic decisions about engineering projects and there is a level of knowledge about engineering that is required to do so. We felt that a course purposely designed for Arts and Commerce students would be a concrete way to address this perceived need. Note that the creation of this course was conceived of and initiated entirely on the engineering side - there was no request from the Faculty of Arts to develop such a course.

\subsection{Consultation with Arts}

As a part of the process of developing the course, we consulted extensively with the Faculty of Arts, with both the Associate Dean and a group of Arts students. We used the results of these consultations in designing the course.

\section{Arts Associate Dean}

We approached an Associate Dean in the Faculty of Arts about our interest in running the course after initial discussions had taken place within engineering.

The Arts degree program has a six-credit Science requirement, aiming to increase and integrate science literacy. This requirement encompasses regular Science degree courses, and courses designed specifically for Arts students. We were told that, while the latter can require less pre-existing knowledge than courses intended for Science students, they do not always provide content that enhances the Arts degree; topics are interesting, but not necessarily well connected to the rest of the Arts program.

Our course was permitted to count toward fulfilling the Science requirement in the Arts degree, despite not falling under the Faculty of Science, and we aimed to meet the spirit of it by providing opportunities for the students to apply their own disciplinary perspective to what they are learning. Furthermore, we saw this as an opportunity to create a platform for transdisciplinary learning for students from different disciplines and varied years of study.

We were additionally told that the students would have completed Grade 11 math, but that there was a fair bit of anxiety about math. The students may have a minimal physical science background (having most often taken only biology at the high school level). Finally, the factors that influence students to take a course included that the course has no final exam, that it is popular or their peers are taking in, and that is it seen as easy or a grade booster, although it was suggested that an interesting and useful course would not necessarily have to be easy.

\section{Arts students (Arts Undergraduate Society)}

The Arts Dean's office also arranged for us to speak with students from the Arts Undergraduate Society about the proposed course. Some of their feedback included:

- Allow students to bring in analysis from their own disciplinary backgrounds

- Introduce the science as needed, rather than all upfront in the course

- Highly desirable to include lab, hands on, and experiential components

- Do not have a traditional final exam

- Have an upper year course number (to suggest a solid disciplinary background required), but have no pre-requisites

- Try to limit group work to class (may be a wide range of schedules)

- Do not have a required textbook

The consulted students were also very focused on the course title (and did not like our working title of "Demystifying Technology"). They wanted a title that indicated the depth of the course, and that spoke to civic engagement, critical thinking, and why understanding engineering is important. The final course title was "The Art of the Possible: An Introduction to Engineering for Non-Engineers".

\subsection{Attracting students}

We made an effort to advertise the course in several ways, to attract a sizable first cohort. First, we contacted the first six students who had enrolled in the course (by the end of September 2016) and asked them why they were planning to take it and how we might get other students interested. Respondents suggested:

- List the course as requiring no science background on the Arts degree science requirement webpage.

- Create course posters to hang in the Arts buildings.

- Advertise it to the Arts advisors.

- Have a syllabus available online.

- Highlight connections to policy and practical applications.

The course was listed as requiring no science background, and a few students who ultimately enrolled said they chose the course at least partly due to this listing. We created posters for the course (Fig. 1) which were put up in the Arts buildings, particularly around advising offices - a few students mentioned that this was how they discovered the course. (One Arts student even showed up, poster in hand, to our offices in the engineering buildings to inquire about the course, which he eventually enrolled in and completed). Arts advisors 
were also contacted to make them aware of the course.

Interestingly, a number of the students in the course were friends, family members, roommates or partners of engineers/engineering students, and one of their professed reasons for taking the course was to better understand how the person close to them thinks and what they do in their respective professional setting. This interest in understanding the engineering mindset (ways of thinking, knowing, and tackling problems) might be leveraged in the future to attract students, including by possibly asking engineering students to tell their non-engineering friends about the course. We are also hoping for word-of-mouth helping with enrollment in the future.
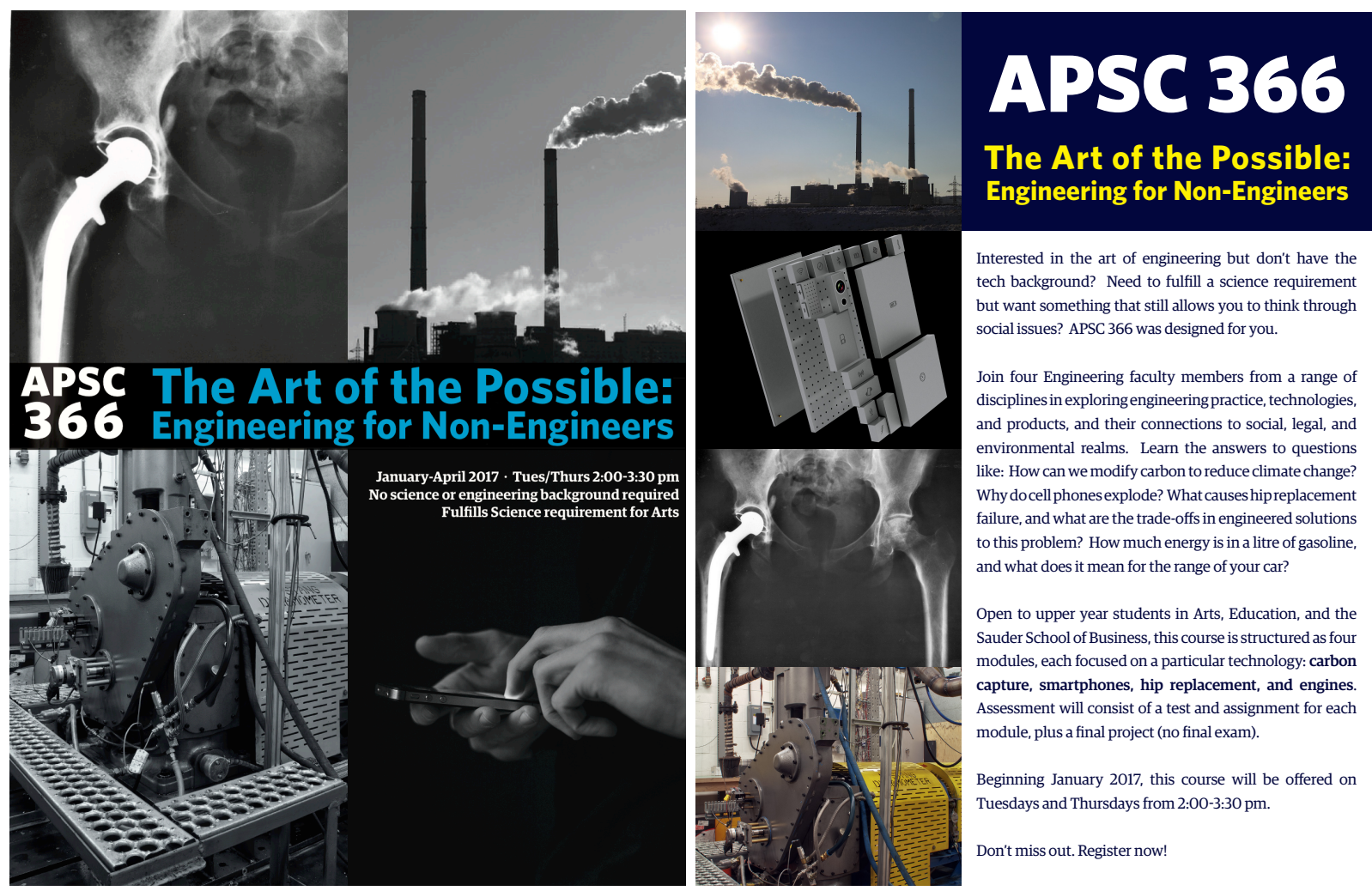

Fig. 1. Two posters created to advertise the course to Arts students (A. Eyking).

\section{COURSE FRAMEWORK}

Our course consists of an introductory module, followed by four technical modules organized loosely around specific technologies in four categories. The module order was primarily arranged based on the instructors' teaching and service obligations, and the final course structure was:

- Module 1: Introduction: engineering problem solving, engineering ethics, graphing,

- Module 2: Carbon management (sustainability)

- Module 3: Human joint replacements (structures)

- Module 4: Smartphones (consumer products)

- Module 5: Engines (energy generation and conversion)

Since we aimed to make this course very interactive with aspects of a flipped classroom, a good deal of the content was delivered through or in conjunction with hands-on (experimental) activities, in-class group work, demonstrations, tours, and mini presentations by students.
Students were often asked to complete pre-readings, previewings of videos, and other work to prepare for classes.

\subsection{Hands-on activities}

The following hands-on activities were carried out with the students during lectures:

- Graphs, plotting, correlation: groups of students were given flexible plastic rulers, coins and clips. Students measured deflection with the same cantilever length of ruler with increasing numbers of coins (linear graph), and the deflection of different lengths of cantilevered ruler with the same number of coins (cubic graph).

- Chemical reaction balancing: conservation of matter and balancing chemical reactions were demonstrated using coloured candies and worksheets, emphasizing candies needed to balance between reactants and products, and that no matter can be created nor destroyed. 
- Water electrolysis: groups of students performed water electrolysis using $9 \mathrm{~V}$ batteries, and captured the resulting gasses in two small test tubes, allowing them to visualize the ratio of hydrogen to oxygen, and test the result by burning the hydrogen.

- Structural strength: groups of students were given various types of pasta (flat, round, small round, tube), and asked to break them via buckling, bending, tension and torsion. Students were asked to rank their estimates of the amount of force to break each shape in the different modes, and to come up with rules for which kinds of shapes/structures better resist the various loads.

- Wear: groups of students determined relationships between surface roughness, load, and wear rate. They sanded small foam blocks using sandpapers of two different grits and applied different levels of force. They measured the blocks with dial calipers (which they were taught how to use).

- Energy conversion systems: in small groups, students inspected a range of consumer energy conversion systems (fluorescent light bulb, electric heater, camp stove, stovetop espresso maker, cigarette lighter, bicycle tire pump), and were asked to identify: relevant energy inputs and outputs, a suitable definition of efficiency, key design considerations that may have been considered.

- Process throughput and bottlenecks: students simulated a production line using a large pool of wooden blocks. Each student represented a process, and used timers on smartphones to hold on to a wooden block (representing the item being produced) for a certain time before passing it to the next process. Provided a visual understanding of a bottleneck. Additional resources (e.g. an extra student) were added to the bottleneck process to demonstrate changes in bottleneck and throughput.

\subsection{Demonstrations}

In addition to the hands-on activities, demonstrations (with and without direct student participation) were used to provide context the concepts being discussed.

- Joint forces: a student was invited to stand on a simple force plate (with the output projected to the class) and then pull up on a strap that went under the force plate, demonstrating the mechanism (muscle tension) by which joint forces can be higher than body weight, even in static positions.

- Sensors in smartphone: projected smartphone sensor readout for class, who then had to deduce the orientation of $\mathrm{x}, \mathrm{y}$, and $\mathrm{z}$ accelerometer axes. Also, the effect of vibrations or knocking the phone sensor on the output was demonstrated. Students were asked to recognize linearity of sensor's transfer function by reading the output of the magnetometer sensor on a smartphone for increasingly stronger magnetic fields generated by increasing number of identical magnets.

- Speaker-as-microphone: showed the output of a function generator on an oscilloscope (amplitude, frequency, and waveform - sinusoidal, square, triangular) - then played the different signals through the speaker. Finally, the speaker was connected to the oscilloscope and demonstrated how signal could be obtained from a human voice (related to the potential for surveillance through devices with speakers).

- Sterling engine: a miniature Sterling engine that runs by sitting on a cup of hot water was used to demonstrate the concept of a heat engine (energy conversion system). This was used to provide a link between the concepts of conservation of energy and internal combustion engines.

\subsection{Other activities}

Finally, a range of other activities were included to expose students to aspects of engineering:

- Montreal sewage problem: the case of the recent Montreal sewage dump into the St. Lawrence was discussed, and students were challenged to come up with other possible solutions (not involving dumping raw sewage in the river). Potential solutions were discussed in light of financial, spatial and logistical considerations.

- Bioenergy Research and Demonstration Facility tour: students visited an on-campus wood waste gasification plant that supplies about $25 \%$ of the campus energy needs for winter, and $100 \%$ for the summer season.

- Needs and specifications: students created needs and specifications for a digital thermometer.

- Find a design failure: students were asked to submit a photograph or bring in an example of a design failure. Failures were discussed, including the nature and severity of the failure, and how engineers might change the design to prevent the failure.

- Class discussions on pre-readings: a number of class discussions and debates were held based on pre-readings, such as a case study of a particular hip replacement failure associated with a company downplaying poor clinical results and a lack of substantial regulatory oversight, resulting in a recall, and industry responses to the Corporate Average Fuel Efficiency (CAFÉ) standards.

- Optional presentation on surveillance through internet devices: students were asked to analyze and present their findings about the inclusion (by manufacturers and/or government agencies) of 
hardware and software that can enable surveillance using smartphones, smart TVs, and other internetconnected devices. Aspects such as technology, ethics, economics, and political implications were discussed in the context of modern, internetconnected consumer devices.

\subsection{Meta-engineering topics}

During each module, instructors presented nontechnical aspects of engineering activities that nonengineers and the public at large is ideally expected to be aware of in the context of public governance, policy making, civic discourse. Among these topics were: engineer's code of ethics, engineering project management, and legal compliance. (Overall course learning objectives can be found in Appendix A).

\subsection{Assessment}

Assessments for each module included an online test on basic engineering concepts, and a blog post aimed at a public audience describing an engineering-related issue making the news, where the students apply their disciplinary background and advocate for a position. Themes for the blog posts were pulled from issues making the news, and students were able to post either privately to blog within the learning management system, or both publically and privately. Students were also expected to comment on other blog posts as part of the assignment. Topics included articulating one's opinion on how to move forward to fight climate change, advocating for design requirements for a patient-administered medical device for remote Indigenous communities, in response to a news article [7], and responding to vehicle emissions standards and the Volkswagen scandal [8] to comment on whether diesel engines should be used in passenger cars.

The online tests were administered through the learning management system, and included multiple choice and short answer questions. Students had about a week to start the test after the associated module finished, and had one hour to complete the test once started.

A final group video project involved evaluating a current issue related to a presented topic, again using each student's disciplinary expertise, and working through multiple perspectives in a transdisciplinary team. The instructors produced a list of topics related to their modules, which was released at the start of the term. Students were assigned to teams which included a mix of discipline and year level, and they could select their topic. Teams produced a proposal fairly early in the term, and presented their final seven-minute video (along with a fact and reference sheet) during our scheduled final exam period. No final exam was given in this course.

\section{REFLECTION ON TEACHING AND STUDENT FEEDBACK}

The instruction team was overall very pleased with the student interest and engagement in the course. We had 27 students complete the term, with good attendance at lectures, and a class average in the mid-seventies.

The dynamic in the course was different from typical engineering core courses, in that all the students specifically chose this course out of a wide range of options they had - they could choose to drop the course (and we had a lot of adds and drops right up to the deadline), but that meant those who remained were fairly highly invested in it. The instructors also were able to mix in a wide range of material about their topics, and select interesting or topical subjects, rather than having a set of topics they must cover (as in engineering core courses). Overall, this made for a very rewarding teaching experience.

\subsection{Level of instruction, complexity, and math}

There appeared to be quite a range of pre-existing student knowledge within the course, which made finding the level somewhat challenging. Some students were very comfortable in math and science, having taken those courses at a high school or even post-secondary level, while many students indicated that they enrolled at least in part because the course did not require a science background. Informal and formal (anonymous) feedback generally told us that our pace was not too fast for the students with the least background, but was a bit too slow for a minority of students who knew more. We were also pleasantly surprised to find the students asking for a little more technical content when we had started off limiting any math, equations, or harder engineering science. In response to student feedback, the course instructors felt that we increased the technical content as we progressed through the modules.

We tried to make explicit connections between the modules, and build upon the material that was presented previously. Instructors attended some of each other's classes and contributed connections directly as part of the class discussion (for example, talking about signal frequency in Smartphones, one co-instructor highlighted how we could talk about the frequency of a heartbeat; and during the activity about wear in joint replacements, another co-instructor talked about the surface roughness (smoothness) of large telescope mirrors and how that was achieved).

We also communicated possible connections within the instructor team informally outside of class, and were able to bring in this material. One example is talking about the correct air-fuel mixture required for engine control, which referred back to chemical equation balancing from the Carbon module. 


\subsection{Student feedback}

Student feedback was solicited throughout the course using anonymous online surveys (during Module 3 at the middle point of the term and at the end of the course), in class directed questions (several times), and written anonymous feedback (at the start of Module 5). Several students provided feedback via email as well.

Ten out of 27 students completed the mid-term survey, and all reported that the course was somewhat meeting, meeting or exceeding expectations. Primary themes were that the hands-on activities and demonstrations were effective, the pre-class videos were useful (although the longer readings were not), class organization could be improved a bit (particularly related to the final project), and students wanted to cover the material in more depth.

Ten out of 27 students also completed the written feedback at the start of Module 5. Students reported enjoying that the material was applicable to "real life", for example ways of living more sustainably or how engine legislation impacts consumers. There were several positive comments about hands-on activities, demonstrations, and videos, and more calls for technical content (while remaining accessible to non-technical students).

Eight out of 27 students completed the final course survey, which was released at the end of classes but prior to the final project presentations. We recognize that this is a low response rate, so the results should be viewed with a critical eye (as we expect only the most engaged students responded), however since this survey was more comprehensive and directly addressed the course goals, we feel it is useful to include in some depth (Table 1).

As the comments throughout the course suggested, responding students did not find the content overly complex or challenging, with the majority selecting neutral or disagreeing with statements about the complexity of the lectures and activities. When asked which modules were the most technically complex, students had a variety of answers. This was surprising, as we had an impression that we were increasing the complexity as the course progressed.

While students were mixed on whether the course was cohesive, given its module-based format, the importance of having cohesiveness was also mixed.

When asked about applications and understanding of engineering topics, a majority of respondents agreed to statements saying they greatly improved their understanding of engineering, and that they would both apply the material in their day-to-day life and apply the material in an academic setting. This touches on three primary goals of the course - to help students understand the engineering that affects their lives and communities, to be able to use this understanding, and to provide a course that enhances their Arts degrees.
Table 1: Final course survey ratings $(n=8)$. SA = Strongly agree, $A=$ Agree, $N=$ Neither agree nor disagree, $D=$ Disagree, $\mathrm{SD}=$ Strongly disagree.

\begin{tabular}{|l|l|l|l|l|l|}
\hline \multicolumn{1}{|c|}{ Statements } & SA & A & N & D & SD \\
\hline $\begin{array}{l}\text { I found the technical lecture } \\
\text { content to be very complex } \\
\text { and/or challenging }\end{array}$ & 0 & 2 & 5 & 1 & 0 \\
\hline $\begin{array}{l}\text { I found the activities } \\
\text { (demonstrations and hands-on } \\
\text { experiments) covering } \\
\text { technical topics to be very } \\
\text { complex and/or challenging }\end{array}$ & 0 & 0 & 3 & 5 & 0 \\
\hline $\begin{array}{l}\text { The modules were well } \\
\text { integrated to provide a } \\
\text { cohesive course }\end{array}$ & 1 & 1 & 2 & 3 & 0 \\
\hline $\begin{array}{l}\text { The integration of the modules } \\
\text { into a cohesive course is } \\
\text { important. }\end{array}$ & 0 & 3 & 2 & 2 & 1 \\
\hline $\begin{array}{l}\text { I expect to apply the material } \\
\text { from this course in my day-to- } \\
\text { day life }\end{array}$ & 2 & 5 & 1 & 0 & 0 \\
\hline $\begin{array}{l}\text { I expect to apply the material } \\
\text { from this course professionally } \\
\text { in the future }\end{array}$ & 1 & 2 & 4 & 1 & 0 \\
\hline $\begin{array}{l}\text { I expect to apply the material } \\
\text { from this course in an } \\
\text { academic setting (e.g. within } \\
\text { another course) }\end{array}$ & 0 & 5 & 1 & 2 & 0 \\
\hline $\begin{array}{l}\text { I have greatly improved my } \\
\text { understanding of the } \\
\text { engineering mindset (how } \\
\text { engineers think about } \\
\text { problems) }\end{array}$ & 1 & 5 & 1 & 0 & 0 \\
\hline $\begin{array}{l}\text { I have greatly improved my } \\
\text { understanding of the type of } \\
\text { constraints and trade-offs } \\
\text { involved in engineering (e.g. } \\
\text { regulations (safety, } \\
\text { environment), physics, costs) }\end{array}$ & 2 & 5 & 1 & 0 & 0 \\
\hline $\begin{array}{l}\text { I have greatly improved my } \\
\text { understanding of some of the } \\
\text { governing principles engineers } \\
\text { use (e.g. conservation of } \\
\text { energy, conservation of mass, } \\
\text { force balance, etc.) }\end{array}$ & 3 & 4 & 1 & 0 & 0 \\
\hline
\end{tabular}

When asked about why they might not expect to apply the course material, one student wrote:

"With questions of usefulness I always think about that oft-cited factoid about how, for every $\$ 1$ invested in NASA, \$7-\$14 dollars is returned to the American economy. I find the class interesting, and there's some tidbits in the class about ceramic medical inserts, or octane numbers, or biofuel, or bitcoin that are useful in an immediate, obvious way, but I suspect that the most 
useful features of this course will reveal themselves through subtler, long-term effects."

Students were also asked about what worked well in the course (specific activities, topics, types of activities). Many of the hands-on activities, demonstrations, and other activities (e.g. field trip, group in-class activities and discussion) were mentioned, as was the mix of lecture and experiential learning within the modules and the pre-class videos and provided lecture slide print-outs. When asked what did not work well, some students noted a disconnect they felt between the content and the online quizzes (which were focused primarily on the technical topics). Other comments related to improvements in instructor and course organization and the exact balance of topics and material.

Seven out of eight student respondents said they would recommend the course to others. They were asked why they would recommend the course (or not), but only those who said they would recommend it provided comments. These included:

- "There's not a lot of opportunities for nonengineering students to make any kind of tentative foray into (or get a good overview of) different engineering disciplines. This was a rare opportunity to get that kind of information."

- "I found it to be a very good introduction to 4 different types of engineering, which gave a me a great introduction to the field of engineering as a whole. The level of technical details were perfect for a non-engineer and the subjects of the modules were all interesting."

- "I really would recommend this course, it can have a large impact on your life learning about other fields and what they do, I wish it was mandatory for all faculties to take this course."

\subsection{Course content}

We felt that the content of the course met the goals and was interesting to the students. While we had a mix of broad (carbon management) and narrow (human joint replacements) topics, this mix seemed to work fine.

\subsection{Assessments}

Based on instructor observations and student comments, there are several areas of improvement in the assessments, particularly the final project.

\section{Tests}

The tests were designed to assess if the students were able to demonstrate understanding of the key technical topics in each module; however, there seemed to be a disconnect between some modules and their associated technical topic tests, as was noted in the student feedback:
"The hip joint replacement and smartphone quizzes were especially unpleasant, I attended the lectures and was still surprised by the questions."

We had each checked with the rest of the instructor team about each module's quiz questions, and no major concerns were raised. It is not clear why this occurred, and more exploration of this issue is needed.

\section{Assignments}

While the intention was for students to bring in their disciplinary background to the assignment blog posts, we found that this background was not apparent to the instructors in the work submitted. It may be that our lack of expertise in these areas meant we did not pick up on this background. We were also surprised that so few students wished to post their work publically.

\section{Final project}

Comments through several venues indicated that one of the main areas that could be improved was the final project organization. Some students indicated that they enjoyed having a video as a final project (and preferred this to a final exam).

Because there was a lot of flux in the class roster prior to the course add/drop deadline (12 students dropped the class and about the same number joined within the first three weeks), the teams were reformed three times. This made it difficult for students to plan and finalize a topic. This dramatic changeover in students was unexpected; it would be very unusual for an engineering class. We also did not have a formal peer grading system for the project, however we plan to implement one after seeing differing levels of contribution from students within a team.

We created a series of topics to select from (or teams could choose their own, as one team did). However, we did not anticipate how limited the understanding of those choices would be. The topic selection had to be made early in the term, before even starting most of the modules. One student later indicated that they chose a familiar topic that they already understood due to concerns about the effect on their grades. The outcome was that, out of six teams, there were two duplicated project topics, and all topics were from only two modules. In future, we plan to review the topics at the start of term so students can feel more confident choosing something they are less familiar with.

We are considering adding a tutorial to the course for the purpose of having time for project work and interaction with instructors on their project topics.

\section{CONCLUSIONS AND RECOMMENDATIONS}

For engineering faculty who are interested, we would highly recommend developing and teaching a course to provide an introduction to engineering for non-engineers. 
It was a rewarding and enjoyable experience for the instructors, and student feedback and in-class discussions suggested that we met our aim of sharing some understanding of the role of engineering in society. The challenge of introducing the perspectives of "how to think like an engineer" without much technical content was a refreshing task for some of the instructors.

\subsection{Recommendations}

- Team teaching: a multi-disciplinary teaching team was a big benefit, both to students and instructors. We had excellent continuous interaction within the instructor team at all stages of the course: development, teaching of individual modules, and post-course reflection and analysis sessions. And students got perspectives from many areas, including connections between fields.

- Fulfilling Science requirement: having the course count toward a degree requirement was important to attracting Arts students. Commerce students did not have this requirement, and we had only one Commerce student enroll.

- Hands-on activities and demonstrations: we heard multiple times that including experiments, demonstrations, and other activities was a very successful aspect of the course. They required some preparation and inventiveness, but were an effective way to deliver technical content without employing math.

- Reduce student angst: As many students will have limited technical knowledge, we suggest taking steps to reduce student concerns of "getting a bad grade". Here we found the lack of a final exam (replaced with video project) and short quizzes effective. For the technical components of the quizzes, it is important to make the expectations clear to the students a priori.

\section{Acknowledgements}

We would like to acknowledge the long list of colleagues who put their time and talents into brainstorming the framework, goals, and some of the content for the course, as well as providing advice from their own experience teaching outside engineering. We would also like to thank Dr. Janet Giltrow who assisted us in her role as Associate Dean, Faculty of Arts and provided us with many insights, and the Arts Undergraduate Society members who shared their feedback with us. Finally, thanks to the brave students who took this course in the first offering - we could not have asked for a better first class.

\section{References}

[1] E. Kullman, C. M. Vest, G. W. Clough, L. Collins, D. P. Giddens, R. Hoffman, R. O. Johnson, V. Kramer, I. Pressley McPhail, E. J. Prendergast, and B. Shanahan, Messaging for engineering: from research to action. National Academies Press, 2013.

[2] D. P. Giddens, R. E. Borchelt, V. R. Carter, W. S. Hammack, L. H. Jamieson, J. H. Johnson, V. Kramer, P. J. Natale, D. a. Scheufele, and J. F. Sullivan, Changing the conversation: messages for improving public understanding of engineering. 2008.

[3] Association of Professional Engineers and Geoscientists of British Columbia, "APEGBC Code of Ethics," https://www.apeg.bc.ca/For-Members/Ethics,Law-and-Conduct\#APEGBCCodeofEthics. .

[4] S. Tobias, "Introduction - Engineering-Enhanced Liberal Education Project, ASEE," 2016.

[5] Engineering-Enhanced Liberal Education Project ASEE, "Case Studies." [Online]. Available: https://www.asee.org/engineering-enhanced-liberaleducation-project/case-studies. [Accessed: 04-May2017].

[6] S. Tobias and J. Krupczak, "Introducing Engineering to Non-Engineering Students: Timing, Variability, Institutional Commitment (Workshop Document)," in ASEE Annual Conference, 2016.

[7] J. Porter, "First Nations man conducts own dialysis treatments to avoid move to the city - Thunder Bay CBC News." [Online]. Available:

http://www.cbc.ca/news/canada/thunder-bay/homedialysis-1.3873291. [Accessed: 04-May-2017].

[8] G. Gates, J. Ewing, K. Russell, and D. Watkins, "How Volkswagen's 'Defeat Devices' Worked," The New York Times. [Online]. Available:

https://www.nytimes.com/interactive/2015/business/int ernational/vw-diesel-emissions-scandalexplained.html?_r=0. [Accessed: 05-May-2017].

\section{APPENDIX A: LEARNING OBJECTIVES}

Upon completion of the course, it is expected that students will be able to:

- Describe qualitatively the fundamental principles, technical limitations and possibilities associated with several specific common engineering products and processes

- Describe engineering practice, and articulate tradeoffs associated with specific technologies and engineering decision-making in general

- Describe the interactions between engineering and social, legal, and environmental realms

- Develop, and communicate to the public, critical analyses of engineering projects/decisions that are making the news, as part of civic engagement 